\title{
The Dialectic between Embodied Experiences and Mathematical Concepts
}

\author{
Commentary on Saxe, de Kirby, Kang, Le, and Schneider \\ Ellice Ann Forman \\ University of Pittsburgh, Pittsburgh, Pa., USA
}

\begin{abstract}
Key Words
Concept development · Mathematics education · Microgenesis · Vygotskian theory
\end{abstract}

In their article, Saxe, de Kirby, Kang, Le, and Schneider [this issue] address a crucial issue in children's mathematical development: how to understand the dialectic between everyday (embodied experiences) and scientific concepts (verbally defined, specialized disciplinary vocabulary). In other words, how can we conceptualize the interplay between bottom-up and top-down learning processes in a classroom community? Although this issue was identified by Vygotsky [1987] 80 years ago, detailed descriptions of its microgenesis ${ }^{1}$ are rare. In addition to articulating the dynamics of this dialectic, Saxe and his colleagues demonstrate how it was used to support students' understanding of several mathematics concepts that have been shown to be difficult to learn (e.g., equivalent fractions).

To illustrate their analytic approach, Saxe et al. draw from a corpus of data collected over 19 lessons in one fifth-grade classroom located in California. Despite their single case study design, they argue that the process by which they conceptualized students' learning could generalize to other classrooms and other content areas. To support this claim, they mention Saxe's previous research in culture and cognition

${ }^{1}$ Saxe [2012] described three levels of change in human activity: microgenesis, sociogenesis, and ontogenesis. He defined microgenesis as short-term shifts when people use cultural tools in new ways, sociogenesis as transformations of collective activity, and ontogenesis as long-term changes in activity over the life span. Similar accounts of developmental change can be found in other sources such as Lemke [2000].

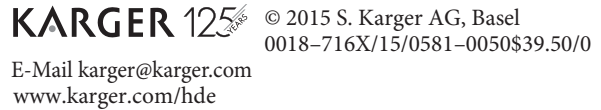

KARGER 125/s @ 2015 S. Karger AG, Basel www.karger.com/hde 0018-716X/15/0581-0050\$39.50/0

\author{
Ellice Ann Forman \\ Department of Instruction and Learning \\ School of Education, University of Pittsburgh \\ 5527 WW Posvar Hall, Pittsburgh, PA 15260 (USA) \\ E-Mail ellice@ pitt.edu
}


[e.g., Saxe, 2012] as well as prior research by other investigators within and outside of the area of mathematics education. One of the sources cited by Saxe et al. is the work of Vasily Davydov, a Russian psychologist who developed a mathematics curriculum based on Vygotsky's theory beginning in the late 1950s.

Two of Davydov's most innovative proposals were to base the instruction of children on: "first establishing contentful abstractions and generalization that would serve as 'cells' of the system, and second, the ascent from the abstract to the concrete" [Davydov, 1988, p. 191, emphasis in the original]. Davydov's approach to developmental education may seem foreign to North Americans whose views of school learning have been influenced more by behaviorism (Gagné's learning hierarchies) and/or constructivism (Piaget's stages). A similar critique of North American curricular dependency on notions of learning hierarchies and overly simplified notions of Piagetian stages has been made by Metz [1995]. Metz identified a number of barriers to designing a developmentally appropriate elementary science curriculum based on limited understanding of Piagetian constructivism that could still be relevant today. One of those barriers is the mistaken idea that young children are "concrete" thinkers who cannot be expected to understand abstract ideas. She showed how this supposed developmental constraint on children's thinking is not supported by many of Piaget's own investigations or by more recent research in children's scientific thinking, including research by investigators like Ann Brown and Joe Campione who were influenced by Vygotsky's theory.

Davydov's curricular applications of Vygotskian theory have been implemented in the United States by some of his former students [e.g., Hedegaard \& Chaiklin, 2005; Schmittau, 2003]. The aim of this commentary is to compare the deeply theoretical and practical research program of Saxe et al. with Davydov's interpretation of Vygotsky's approach to developmental education. Due to the constraints of this brief commentary, I will rely upon Schmittau's interpretation of Davydov's work in elementary mathematics to illustrate the fundamental principles that guided the teaching and learning of mathematics in North America and in Russia under Davydov's curricular framework.

Although Davydov (1930-1998) was too young to have met Vygotsky, he was influenced by Vygotsky's collaborators Luria (1902-1977) and Leont'ev (1903-1979) and other members of the Vygotskian school (e.g., El'konin) [Davydov, 1988]. One central principle of Davydov's approach was that "the basis of all our mental functions, including thought, lies (in) the real object-oriented activity of collaborating people" [Davydov, 1988, p. 180].

Schmittau [2005] outlines three fundamental and interconnected aspects of Vygotsky's theory that Davydov employed to create his curriculum: first, the designer must begin with the most generalized (theoretical) concepts from the discipline; next, one moves from these abstract concepts to their concrete instantiation in activities that make sense to children; and, finally, one needs to incorporate the use of psychological tools (such as visual representations or material objects) in instruction. In mathematics, that means grounding the curriculum in real numbers (the numerical group that includes zero, positive and negative integers as well as rational and irrational numbers) and not in its more limited subgroup of natural numbers (positive integers). In contrast, most constructivist curricular approaches in North America are built on children's prior knowledge of natural numbers used for counting. Those frameworks are strongly criticized by Russian-influenced theo- 
rists like Schmittau [2003, 2005] because they are not based on sufficiently general notions of mathematics. As a result, many generalizations based on natural numbers (e.g., the multiplication of positive integer quantities results in larger quantities) may be contradicted by rational numbers and are, thus, barriers to further learning. Nevertheless, the Russian approach does not remain highly abstract (as in the "new math" of the 1960s and 1970s in the United States) but quickly evolves into applications of numbers to empirical quantities via the measurement of the characteristics of physical objects (in terms of length, area, volume, and weight) [Schmittau, 2005].

Finally, measurement depends upon the use of developmentally appropriate psychological tools such as number lines, standard and nonstandard units of measurement, or three-dimensional objects (e.g., Cuisenaire rods). In this way, even children as young as first or second grade are introduced to the abstract features of familiar physical objects by asking them to compare those objects in terms of length or other characteristics. Standard measuring tools (rulers, graduated cylinders) are not introduced until the children recognize the nature of measurement by units (e.g., units must be iterated along a dimension with no overlaps or gaps) and the value of standardization [Lehrer, 2003]².

One advantage of using real or rational numbers to ground early instruction in mathematics is that they are continuous, just like measurements of physical objects (and unlike positive integers) ${ }^{3}$. Thus, Schmittau [2005] argues that the more general characteristics of the more inclusive group of real numbers offer children experiences that will serve them well when they need to apply them to algebraic as well as arithmetic operations. In fact, in Davydov's curriculum, first and second graders are introduced to proto-algebraic expressions in connection with representations of length. For example, they are shown a visual representation of a line that is divided into the following parts: A (its entire length labeled on the left side); B ( $75 \%{ }^{4}$ of its length, labeled on the right side); and C ( $25 \%$ of its length, labeled on the right side). In this way, the children can make sense of $\mathrm{A}=\mathrm{B}+\mathrm{C}$. These proto-algebraic expressions are then further explored in terms of part-whole relationships such as $\mathrm{B}=\mathrm{A}-\mathrm{C}$ or $\mathrm{C}=\mathrm{A}-\mathrm{B}$ in terms of concrete lengths.

Using these same proto-algebraic expressions, children then apply these concepts about length to other quantities including discontinuous ones. Thus, children are introduced to arithmetic operations on physical objects as interrelated to the "actions of composing and decomposing quantities" [Schmittau, 2003, p. 234]. Addition and subtraction are viewed as complementary actions and not as separate operations on abstract symbolic objects.

Specifically designed schematic models and activities were part of Davydov's carefully sequenced curriculum [Schmittau, 2003]. For example, first graders are repeatedly required to build and measure quantities to prepare them for more complex problems in second grade (such as measuring a large quantity with a very small unit

\footnotetext{
${ }^{2}$ Saxe et al. refer to these as the sensorimotor actions of counting, displacing, and splitting.

${ }^{3}$ See Strom, Kemeny, Lehrer, and Forman [2001] for a similar instance of instruction in another North American elementary school classroom community where embodied measurement activities were used to make advanced mathematical concepts meaningful and to enculturate disciplinary practices such as argumentation.

${ }^{4}$ Note: numbers are not used in the representations that children see. For example, segments of a line are given different colors to represent the connected parts of the whole line.
} 
until they recognize the need to redefine units to make the process more efficient). Schmittau [2005] reports that, when she used Davydov's curriculum in grades one through three in a school in upstate New York, third graders were able to solve problems using proportions, rate, time and distance - topics that are viewed as challenging for much older children in North America.

How does the enacted curriculum from the case study in California described by Saxe et al. compare with Davydov's curriculum as employed in New York by Schmittau [2005]? First, both curricular approaches were based on Vygotsky's [1978] notions of concept development. Second, both classroom communities made repeated use of psychological tools such as the number line or other mathematical objects (visual representations, Cuisenaire rods, and a carefully sequenced set of mathematical problems) to support children's embodied activities in order to help them make sense of mathematical concepts. Third, both approaches were based on children's intuitive knowledge of measurement (e.g., sharing food items) as a way to conceptualize the ordinal and cardinal nature of continuous and discontinuous quantities. Finally, both curriculums were built on perspectives of numbers as representing continuous quantities (either rational or real numbers).

Why are Vygotsky's ideas about the dialectic between everyday and scientific concepts still relevant for developmentally appropriate curriculum? Davydov [1995] asked us this question 20 years ago, and we find ourselves continuing to answer that question today. In Davydov's $[1988,1995]$ writings, he argued that the germ cell of learning begins when the abstract ascends to the concrete. This paradoxical statement can easily mislead us into thinking that young children's education must begin with abstractions. However, a closer reading of Schmittau's [2003, 2005] application of Davydov's ideas suggests that the curriculum builds on children's understandings of everyday concepts (such as sharing objects) in order to prepare them for both more sophisticated activities with objects and mathematical abstractions. Saxe et al.'s curriculum envisions the relationship between sensorimotor actions and important mathematical definitions and operations as synergistic. This seems related to the approach recommended by Davydov and implemented by Schmittau [2003, 2005].

In a similar fashion, Metz [1995] concluded that educators have underestimated children's capabilities and have "created a vicious cycle of impoverished domainspecific knowledge and impoverished inquiry" in elementary science education [p. 121]. Instead she recommends that a carefully sequenced curriculum for elementary school children could be used to build upon students' prior knowledge of the natural world so that children's scientific inquiry activities are guided less by a sense of developmental constraints and more by a willingness to make authentic scientific inquiry accessible to them. This same stance toward children's early learning about rational or real number operations seems to characterize the work of Saxe et al. and Schmittau. Thus, these educational researchers agree that a developmental approach to curriculum and instruction requires careful attention to children's emerging capabilities during responsive instruction and thoughtful analysis of the affordances and constraints of the discipline they are learning. These theoretical and practical challenges were apparent to Vygotsky during his lifetime, and they are still relevant today. 


\section{References}

Davydov, V.V. (1988). The concept of theoretical generalization and problems of educational psychology. Studies in Soviet Thought, 36, 169-202.

Davydov, V.V. (1995). The influence of L.S. Vygotsky on education: Theory, research, and practice. Educational Researcher, 24, 12-21.

Hedegaard, M., \& Chaiklin, S. (2005). Radical-local teaching and learning: A cultural-historical approach. Aarhus, Denmark: Aarhus University Press.

Lehrer, R. (2003). Developing understanding of measurement. In J. Kilpatrick, W.G. Martin, \& D. Schifter (Eds.), A research companion to the principles and standards for school mathematics (pp. 179-192). Reston, VA: National Council of Teachers of Mathematics.

Lemke, J.L. (2000). Across the scales of time: Artifacts, activities, and meanings in ecosocial systems. Mind, Culture, and Activity, 7, 273-290.

Metz, K.E. (1995). Reassessment of developmental constraints on children's science instruction. Review of Educational Research, 65, 93-128.

-Saxe, G. (2012). Cultural development of mathematical ideas: Papua New Guinea studies. New York, NY: Cambridge University Press.

-Schmittau, J. (2003). Cultural-historical theory and mathematics education. In A. Kozulin, B. Gindis, V.S. Ageyev, \& S.M. Miller (Eds.), Vygotsky's educational theory in cultural context (pp. 225-245). New York, NY: Cambridge University Press.

Schmittau, J. (2005). The development of algebraic thinking: A Vygotskian perspective. ZDM, 37, 16-22.

Strom, D., Kemeny, V., Lehrer, R., \& Forman, E.A. (2001). Visualizing the emergent structure of children's mathematical argument. Cognitive Science, 25, 733-773.

Vygotsky, L.S. (1978). Mind and society: The development of higher mental processes. Cambridge, MA: Harvard University Press.

Vygotsky, L.S. (1987). The collected works of L.S. Vygotsky: Vol. 1. Problems of general psychology (N. Minick, Transl.) (R.W. Rieber \& A.S. Carton, Eds.). New York, NY: Plenum Press. 